\title{
GROUND STEREOPAIR PHOTOGRAPHS
}

\author{
BY G. D. DWYER ${ }^{1}$
}

Employed by Nova Scotia Department of Lands and Forests as Student Assistant during the summers from 1946 to 1950 inclusive. Graduated from the Maritime Forest Ranger School in December, 1950. Commenced continuous employment with Nova Scotia Departments of Lands and Forests in January, 1951, as Provincial Forest Ranger. Granted leave of absence from that Department for the past college year, when he completed freshman year at University of New Brunswick (Forestry). At present attending U.N.B. in second year of forestry.

Methods of obtaining photographs that can be viewed in the third dimension have been developed but are either impracticable to the forester or very expensive. These notes propose to show that effective results in obtaining photographs for three dimension use is simple, inexpensive, and highly practicable, and that only a hand camera is needed.

It was found by experiment that the following procedure resulted in photographs that could be viewed with a pocket stereoscope to give excellent third dimension.

1. The subject or area of interest is chosen and an axe, pair of callipers, or any piece of available equipment to denote relative size, is placed in the area of interest. Exposure is determined.

2. The subject should be photographed so as to get as much depth as possible, therefore, the use of small apertures to increase the depth of focus is desirable. Excellent detail is obtained when the photographs are taken on a hazy day.

3. Certain factors must be considered when taking the photographs. The camera is held to the left side of the body, the picture taken, and keeping the camera in the same horizontal plane another picture is taken approximately six inches to the right of the first. The fact that neither a tripod nor stereo attachment head is needed should be noted. It is desirable to obtain maximum overlap. This is achieved by aiming the camera at exactly the same spot for each picture, the viewfinder being used like the sights on a rifle. Cross-hairs in the viewfinder are helpful and the axe or callipers can be used as the "target".

4. The accompanying photographs were taken with a Rolleicord camera. Contact prints on Kodak single weight Velox Unicontrast paper were prepared and mounted as shown in Figs. 1 to 6 . This camera produced photographs $21 / 4$ by $2 \frac{1 / 4}{4}$ inches which were mounted side by side (the photo taken on the right being mounted on the right) thus giving the average interpupillary distance.

During the summer of 1954 , fifty stereopairs were taken using the above

\footnotetext{
${ }^{1}$ Dept. of Lands and Forests, Nova Scotia. Submitted for publication September 9, 1955.
} 
procedure, and all gave good third dimension when viewed with the Abrams Pocket Stereoscope. Exposures ranged from 1/5 to $1 / 100$ of an second, and from $\mathrm{f} 5$ to $\mathrm{f} 22$.

If the reader is interested in referring to the more technical details on the subject, articles by Miller (1943) and Steigerwaldt (1950) are suggested.

\section{REFERENCES}

MILLER, C. I. 1943. Three-dimensional photography for the forester. Jour. of For,, 41 (6): 406-410.

STEIGER WALDT, E. F. 1950. Stereotypes for aerial photo interpreters. Jour. of For., 48 (10): 693-696.

\section{CAPTIONS}

(See Opposite Pages)

FIGURE 1. Stereopair taken in old growth hemlock stand averaging 60 cords per acre. Plus $x$ film, 1/5, f5.6 (An old stump was used as a support).

FIGURE 2. Stereopair taken in red pine stand averaging 24 cords per acre. Plus $x$ film, 1/50, f8.

FIGURE 3. Stereopair taken in beech stand. Ilford HP3 film, 1/25, f11.

FIGURE 4. Stereopair taken in a balsam fir-white birch type. Plus $x$ film, 1/25, f5.

FIGURE 5. Stereopair showing black spruce bog type. Ilford HP3 film, 1/100, f16.

FIGURE 6. Stereopair showing pulpwood. Note excellent detail of near and distant stacks. Plus $x$ film, $1 / 100, f 16$. 

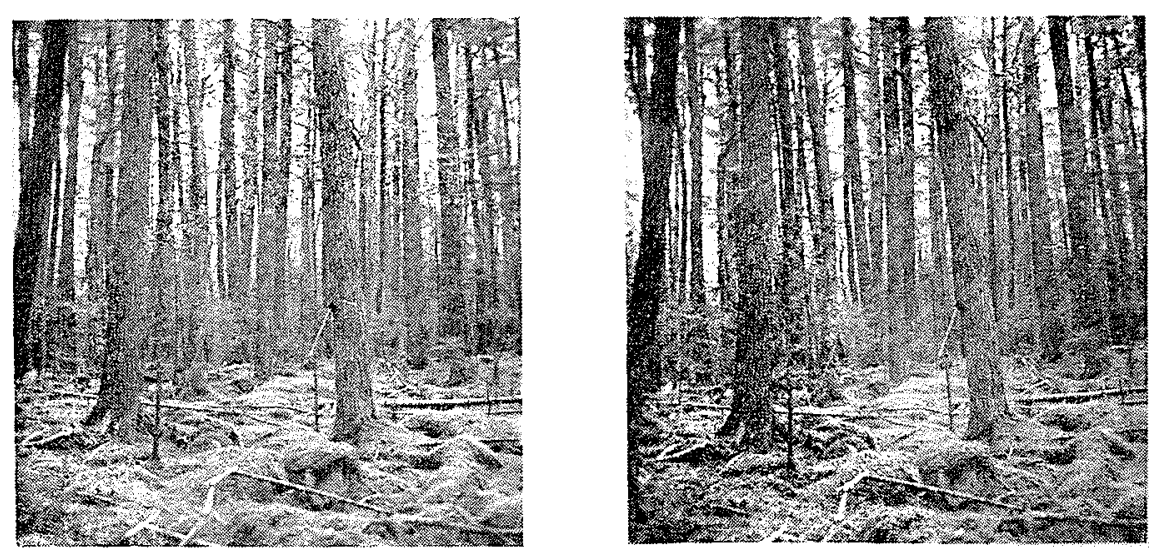

Fig. 1.
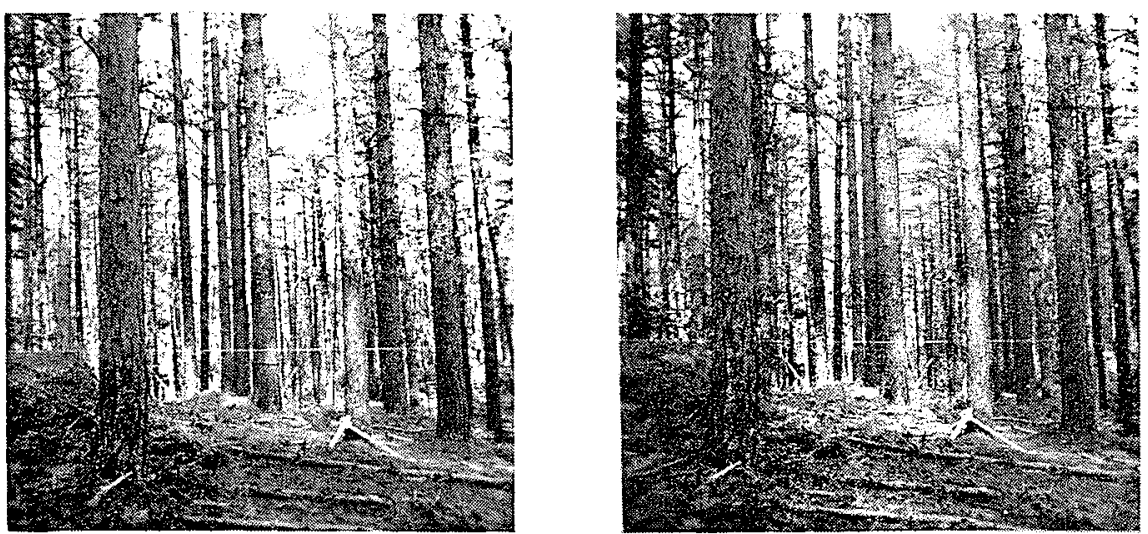

Fig. 2
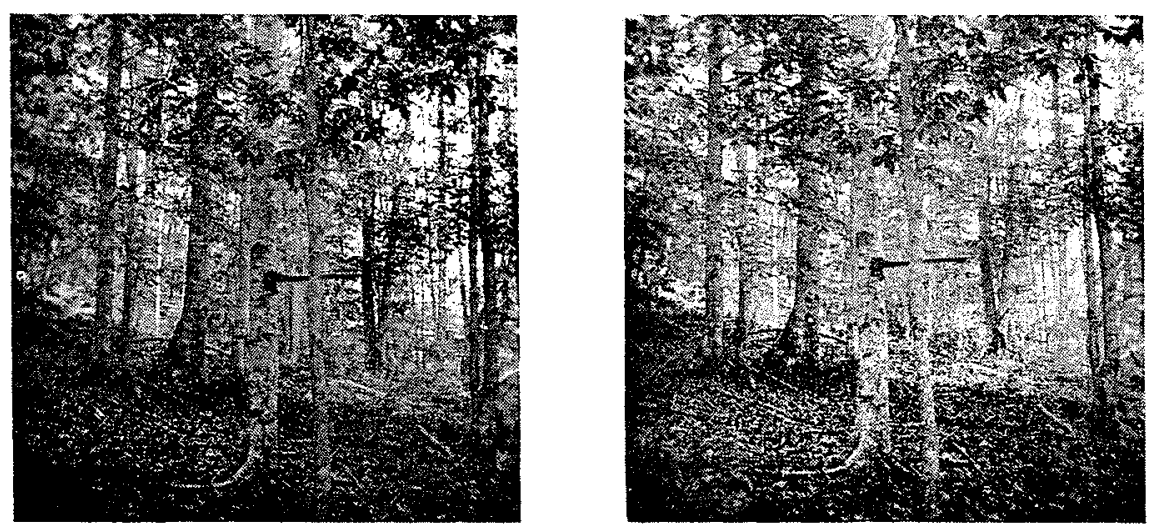

Fig. 3 . 


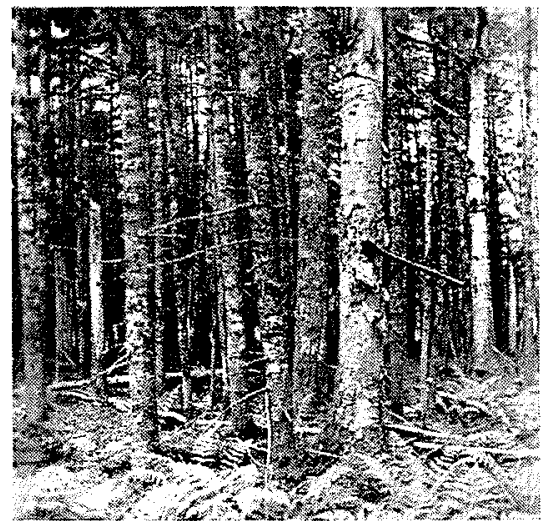

Fig. 4 .

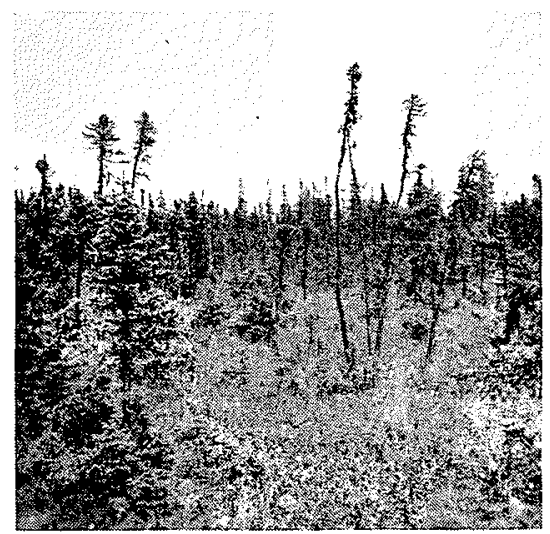

Fig. 5 .

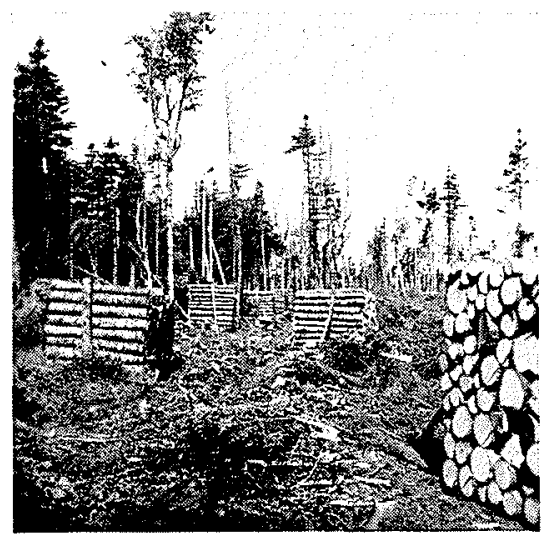

Fig. 6 .
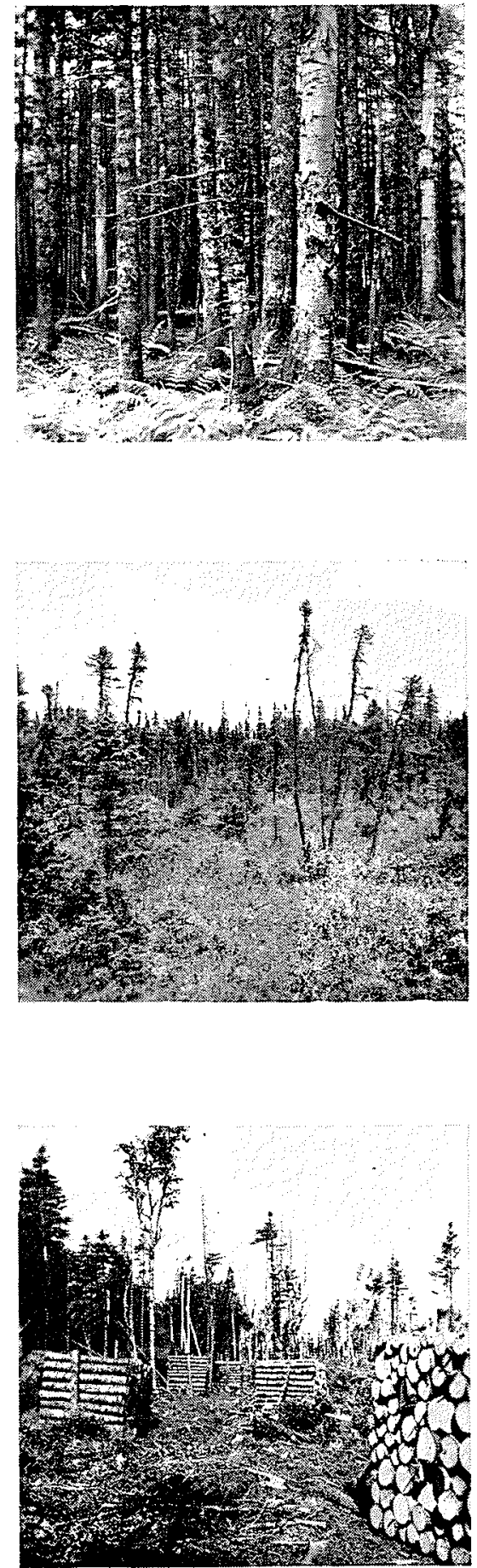